\title{
Monthly range of adolescent orangutans (Pongo pygmaeus wurmbii) based on fruit availability in Tuanan Orangutan Research Station, Central Kalimantan, Indonesia
}

\author{
FAJAR SAPUTRA ${ }^{1,3, \vartheta}$, DYAH PERWITASARI-FARAJALLAH ${ }^{2}$, SRI SUCI UTAMI-ATMOKO ${ }^{3}$, \\ TOMI ARIYANTO ${ }^{3}$, MARIA A. VAN NOORDWIJK ${ }^{4}$ \\ ${ }^{1}$ Program of Animal Sciences, Department of Biology, Faculty of Mathematic and Natural Sciences, Institut Pertanian Bogor, Bogor 16680, West Java, \\ Indonesia. Tel./fax.: +62-251-8622833, "email: fajarsaputra56@gmail.com \\ ${ }^{2}$ Primate Research Center, Institut Pertanian Bogor; Department of Biology, Faculty of Mathematic and Natural Sciences, Institut Pertanian Bogor. Bogor \\ 16680, West Java, Indonesia \\ ${ }^{3}$ Primate Research Center, Universitas Nasional; Faculty of Biology, Universitas Nasional. Jakarta 12520, Indonesia \\ ${ }^{4}$ Anthropological Institute and Museum, University of Zurich, Winterthurerstrasse 190, 8057 Zurich, Switzerland
}

Manuscript received: 11 March 2017. Revision accepted: 13 September 2017.

\begin{abstract}
Setyawan. 2017. Monthly range of adolescent orangutans (Pongo pygmaeus wurmbii) based on fruit availability in Tuanan Orangutan Research Station, Central Kalimantan, Indonesia. Biodiversitas 18: 1445-1452. Adolescent orangutans become competitors with mothers supporting newborn infants. Thus, adolescent orangutans must coordinate with other orangutans in order to find fruit. How adolescent orangutans respond is reflected in the size and utilization of their home range area. The aims of our research were to determine (i) fruit availability, as an important component of orangutan diet, (ii) and the effect of fruit availability on home range use by adolescent orangutan. This research was conducted from August 2013 to July 2014 in Tuanan Orangutan Research Station, Central Kalimantan. The fruit trail method was used to estimate abundance of fruits (both from trees and lianas).Fallen fruit on census trails was assessed once per month, while focal animal sampling was used to estimate the home range by tagging a GPS point every 30 minutes during the tracking of an orangutan. In total, 62 tree and 15 liana species included in the known orangutan diet were fruiting during this study period. The highest period of fruit abundance for orangutan food occurred in November until January. Adolescent orangutans responded by increasing their monthly ranging area during this time of high fruit availability and decreased their range when fruit availability was low. Adolescent orangutans often used areas in their monthly range that had a high to medium abundance of fruit trees. When the number of trees bearing fruit decreased (low period), adolescent orangutans changed their monthly range to areas that consisted of medium to high abundance of liana fruit. Their ranging strategy optimized use of low quality habitat in order to survive in degraded forests.
\end{abstract}

Keywords: Adolescent orangutans, home range, fruit, tree, liana

\section{INTRODUCTION}

Bornean orangutans (Pongo pgymaeus) are one of the most critically endangered primates in the world (Ancrenaz et al. 2016). Bornean orangutans are widely spread over the island, mainly inhabiting peat-swamp and lowland forest. Bornean orangutans still have a larger population size than Sumatran orangutans, however, the number of Bornean orangutans is declining faster than that of Sumatran orangutans (Wich et al. 2008). Currently, deforestation is the greatest threat to orangutan populations. In the period from 1980 to mid-1990s, Indonesian forests suffered from conversion into agricultural, plantation, and residential land; forest fires; and unsustainable exploitation of forest resources (Soehartono et al. 2007). Moreover, humanorangutan conflict and killings occur in Borneo and is one of the serious threats to conservation of this species (Wich et al. 2008; Abram et al. 2015).

Pongo pygmaeus wurmbii is one of the three currently recognized subspecies of Bornean orangutan. This taxon is found in West Kalimantan (Indonesia) from the south part of the Kapuas River to the eastern Barito River in Central
Kalimantan (with a few individuals in South Kalimantan province) (Goossens et al. 2009). This taxon has the largest population of the three Bornean orangutan subspecies, with 34,975 individuals in total (Wich et al. 2008).

Orangutans are frugivorous primates, meaning that a large proportion of their diet is composed of fruit (Galdikas 1988). Orangutans may also consume leaves, flowers, pith, cambium, soil, insects, small vertebrates (such as gray tree rat and slow loris) and (bird-) eggs. Orangutan diet is influenced by ecological factors (the habitat type and the habitat quality) and by orangutan status (wild or rehabilitant) (Russon et al. 2009). To fulfill their food and reproduction needs, orangutans range across their habitat (Singleton et al. 2009).

The accumulation of daily ranges results in a "home range". The home range of an orangutan is influenced by age, sex, and habitat (Singleton et al. 2009; Singleton and van Schaik 2001). Male orangutans tend to disperse from their birth area, while females are philopatric or tend to settle as close as possible to (and often overlapping with) their birth area (Arora et al. 2012; van Noordwijk et al. 2012). Adolescent female orangutans will adjust their 
ranging in accordance with adult female orangutans already in the area. On the other hand, a male orangutan with broad cheek pads (an adult or flanged male) will permanently settle outside of his birth area. A male orangutan without cheek pads (an adolescent or unflanged male), sometimes stays in his birth area or returns to his birth area after ranging in another place (Morrogh-Bernard et al. 2011).

Fruit availability varies over time. Orangutans respond to this variable fruit availability by changing their ranging strategy and the composition of their food (Knott et al. 1998; Morrogh-Bernard et al. 2009). Independent adolescent orangutans will become competitors with mothers supporting newborn infants. This condition forces adolescent orangutan to adjust their ranging in response to other orangutans in order to find enough fruit. Orangutan responses to fruit availability are not only reflected in the size of their range, but also in how the home range is used (Wartmann et al. 2010).

The Tuanan Orangutan Research Station (TORS) is in a peat swamp forest inhabited by orangutans. In the past, this area suffered 'selective' commercial logging activity by companies as well as illegal logging by local communities (van Schaik et al. 2005). Thus, a lot of gaps in the forest canopy were made, which caused the growth of pioneer plants, such as lianas. Another ongoing impact from logging in TORS is the continued loss of water from the peat through canals which were dug and used to transport timber towards the Kapuas River. All these conditions can change the pattern of food plant production, which may affect orangutan home range use.

Currently, there is a lack of information about the home ranges of adolescent orangutans and their response to fruit availability. Therefore, the aims of the research reported in this paper were to identify (i) fruit availability from trees and lianas able to be used by orangutan as food, and (ii) the home range use by adolescent orangutans, based on fruit availability.

\section{MATERIALS AND METHODS}

\section{Study area}

The research was conducted from August 2013 to July 2014 in Tuanan Orangutan Research Station (TORS), Tumbang Mangkutub Village, Mentangai District, Central Kalimantan, Indonesia. The study area is a degraded peat swamp forest consisting of about 1,003 ha which is located approximately $0.4-1.5 \mathrm{~km}$ east of the Kapuas River. TORS is part of the Mawas Conservation Area managed by the Borneo Orangutan Survival Foundation (BOSF). The study area supports a high density of orangutans of ca. 4.25 individuals per $\mathrm{km}^{2}$ (van Schaik et al. 2005).

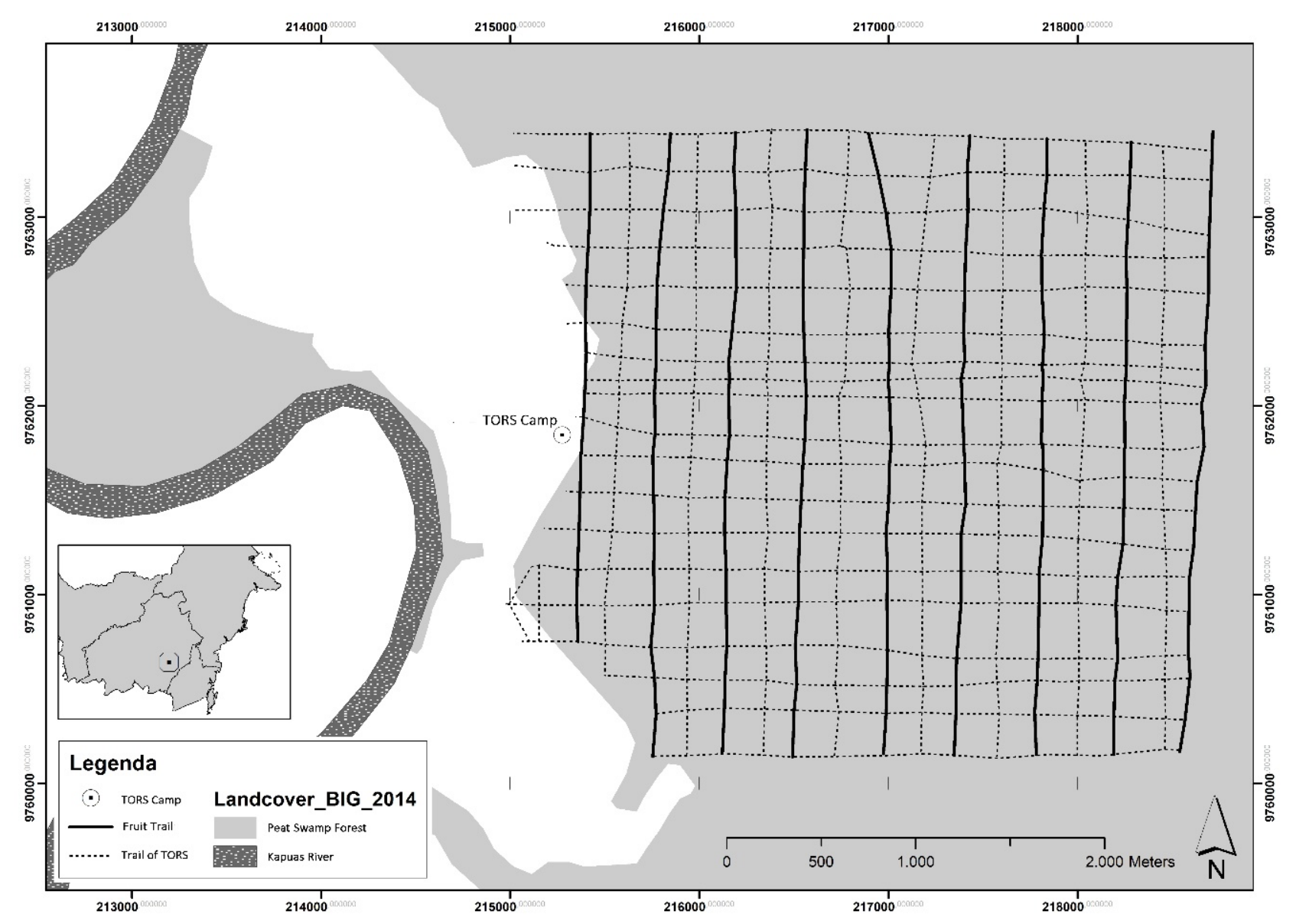

Figure 1. Fruit trail design (black lines) in Tuanan Orangutan Research Station, Central Kalimantan, Indonesia $\left(2.151^{\circ} \mathrm{S} ; 114.374^{\circ} \mathrm{E}\right)$. 
Table 1. Adolescent orangutans as research objects

\begin{tabular}{lllll}
\hline Name & Gender & Age & Independence level & Total number of waypoints (monthly data) \\
\hline Milo & Female & 13 years & Independent & $745(\mathrm{n}=5: 91,200,106,144,206)$ \\
Jip & Male & 8 years & Dependent & $469(\mathrm{n}=4: 153,114,116,86)$ \\
Ipsy & Female & 7 years & Dependent & $438(\mathrm{n}=3: 113,139,186)$ \\
\hline
\end{tabular}

\section{Study objects}

Research objects were fruiting plants and adolescent Bornean orangutans. The data for fruiting plants were divided into two groups: lianas and trees. Three adolescent Bornean orangutans were observed: Jip, Milo and Ipsy. Jip and Milo are cousins (their mothers are maternal sisters), but Ipsy is unrelated to them (Table 1). The number of waypoints collected for each adolescent orangutan varied, see Table 1.

\section{Observation of fruit availability}

The fruit trail method was used to estimate fruit availability on a monthly basis along a designated trail (van Schalk et al. 1995; Buij et al. 2002). Observations were made on nine north-to-south trails, with a length of 3.0-3.2 $\mathrm{km}$ each $(28 \mathrm{~km}$ in total) and approximately 400 metres distance between trails (Figure 1). Trails were designated to get data that represented the entire TORS area. When a fruiting plant was found, its coordinates were determined using a GPS device, and we recorded its species (all fruit species were identified first by local assistants, later verified by a botanist: Ambriansyah).

\section{Observation of adolescent orangutan travel distance and monthly range}

The focal animal sampling method was used to assess how far the adolescent orangutans travel and their monthly range use. We followed and observed an orangutan from wake-up time until night-time nesting for 2-10 days and then repeated this after an interval $>40$ days. Data collection was recorded by a research team who have passed an Inter-Observer Reliability (IOR) test. We obtained geographic locations using a hand-held GPS unit by tagging a point every 30 minutes and every time the orangutan made a nest (van Schaik and van Noordwijk 2013).

\section{Data analysis}

Fruit abundance is defined as the number of trees and lianas bearing fruit per kilometer along a trail. Fruit abundance is used to determine the fluctuation in fruiting plants every month (van Schaik et al. 1995). The relationship between fruit abundance of trees and lianas was tested through Pearson's correlational tests. Spatial patterns of fruit abundance (only fruit used by orangutans as food) every month was analyzed by the Kriging interpolation technique (Mkrtchyan2004) using ArcGIS ver.9.3 software. Our intention was to categorize the area based on productivity level each month (Ariyanto 2015).The three productivity levels (fruit sources) were: (i) low (white colour: tree 0-13.50 fruits $/ \mathrm{km}$ and liana $0-11.50$ fruits $/ \mathrm{km}$ ); (ii) medium (Grey colour: tree 13.51-27.00 fruits $/ \mathrm{km}$ and liana 11.51-23.00 fruit $/ \mathrm{km}$ ); (iii) high (black colour: tree 27.01-81.00 fruits/ $\mathrm{km}$ and liana 23.01-69.00 fruit $/ \mathrm{km})$.

The travel distances of the adolescent orangutans for one day were approximated by summing the distances between all half-hour locations for one day of pursuit. The monthly range of the adolescent orangutans was analyzed with the Kernel Density Estimator (KDE) method, which is a non-parametric analytical method widely used to estimate home range (Laver and Kelly 2008). Monthly range analysis used ArcGIS ver.9.3 software with ABODE v.5 extension. Potential relationships between the number of waypoints and home range size were tested through Pearson's correlational tests.

Effect of fruit availability on the home range use by adolescent orangutans was analyzed by determining the overlaps between maps of fruiting plants and maps of home range. The results estimated the area of utilization as a proportion (\%) of the orangutans' home ranges, based on the productivity levels of fruit (trees and lianas) each month.

\section{RESULTS AND DISCUSSION}

\section{Fruit availability}

Our research recorded 113 species of fruiting plants in total, with the number varying between 29 and 44 species each month. The number of fruiting plants that was known to be orangutan food was $68 \%$ of the total number of species found. During the research period, the fruiting plants consisted of 62 species of trees and 15 species of lianas. This number of species used by the orangutans for fruit food during our research is fewer than has been observed previously, in the years since 2003 (Russon et al. 2009). On the other hand, comparison with data from the peat swamp forests in Sebangau, reveal no real difference in the fruiting plant species used as orangutan food between these two sites (Harrison 2009; Harrison et al. 2010).

The pattern of fruit abundance in TORS observed in this research did not fluctuate widely throughout the year. The fruit was always available, with the highest peak from November to January. The Kapuas River provides nutrient inputs for TORS. Peat swamp forests are low in nutrients but periodically may receive additional nutrients from aerial precipitation and seasonal river flooding (Page et al. 199; Vogel et al. 2015). This condition contrasts with what is observed in dryland forests dominated by 
Dipterocarpaceae. There, mast-fruiting events result in wide fluctuations (Cannon et al. 2007; Wich et al. 2011).

In our study, there were more fruiting trees per $\mathrm{km}$ than fruiting lianas in all months except for August 2013 (Figure 2 ). There was no significant correlation between fruit abundance of trees and lianas (Pearson's correlation coefficient $=0.371 ; p>0.05 ; n=24)$. The highest period of fruit tree abundance occurred from November until January, while the lowest period occurred from April until August. On the other hand, lianas had a different pattern, with the highest period occurring twice, from November until January and April until June, but the lowest period occurring from February until March and August until October (Figure 2). Highest and lowest monthly periods of fruit abundance in this research period were not different from what has been observed in previous research at TORS (Vogel et al. 2009; Ariyanto2015; Vogel et al. 2015; Vogel et al. 2016). Fruiting plant abundance every month is influenced by rainfall. Fruiting plant abundance is higher in the rainy season than in the dry season (Ariyanto2015; Harrison et al. 2016). Even so, the fruit availability pattern that we observed differed between lianas and trees. Lianas were seen in fruit more often per year than trees. This resulted in a very fluctuating pattern of fruit availability in lianas.

The spatial distribution of fruit abundance between lianas and trees differed. Fruiting trees were distributed uniformly throughout the habitat, so that the area of highproductivity changed location every month. On the other hand, the liana's fruit abundance was clumped in the western and southern area of TORS; thus, the highproductivity liana habitats were concentrated there every month (Figure 3). This condition is influenced by the vegetation conditions in TORS. The southern part is closest to a village and was (and still is) used for illegal logging. In the past, massive destruction, forest fire, and road construction occurred in the western area. Both conditions caused gaps which affect liana growth (Schnitzer and Carson 2001; Letcher 2014). In TORS, only the southern part of study area has liana-dominated gaps that leave tangles of lianas on the forest floor even after canopy closure (Letcher 2014).Lianas are pioneer plants, so they grow easily in degraded forests. Previous research has shown that lianas in disturbed forests (succession) have a higher density than in undisturbed forests (Ding and Zang 2009; Addo-Fordjour et al. 2012; Ledo and Schnitzer 2014; Barry et al. 2015).
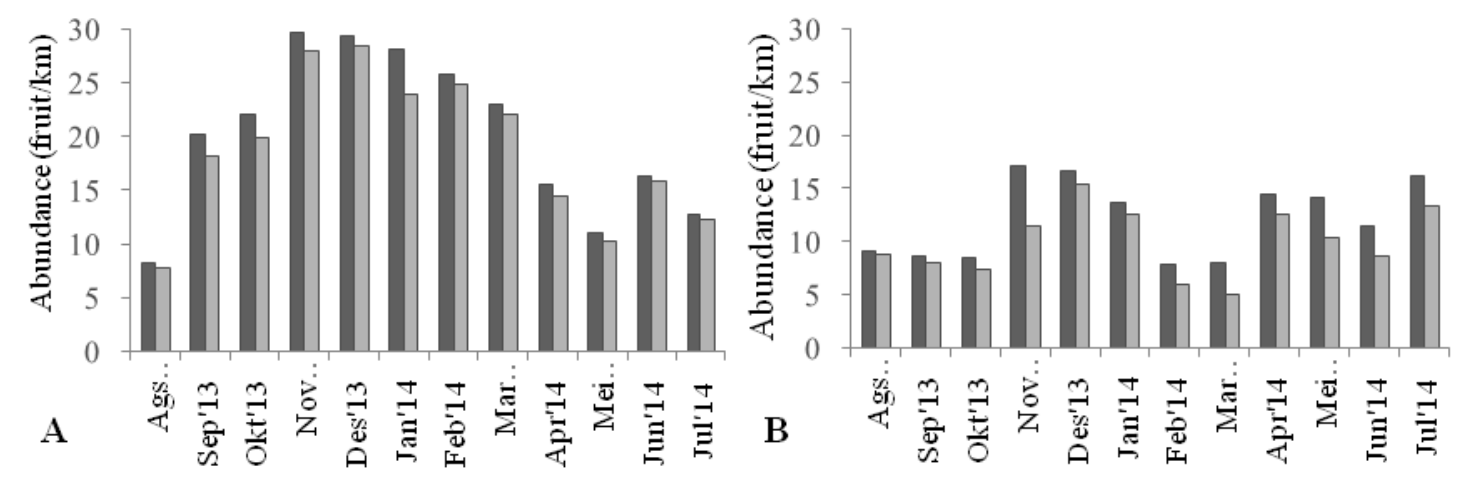

Figure 2. Abundance of fruiting trees (A) and lianas (B) each month in TORS ( $\square$ All fruit; $\square$ Fruit used by orangutan as food)
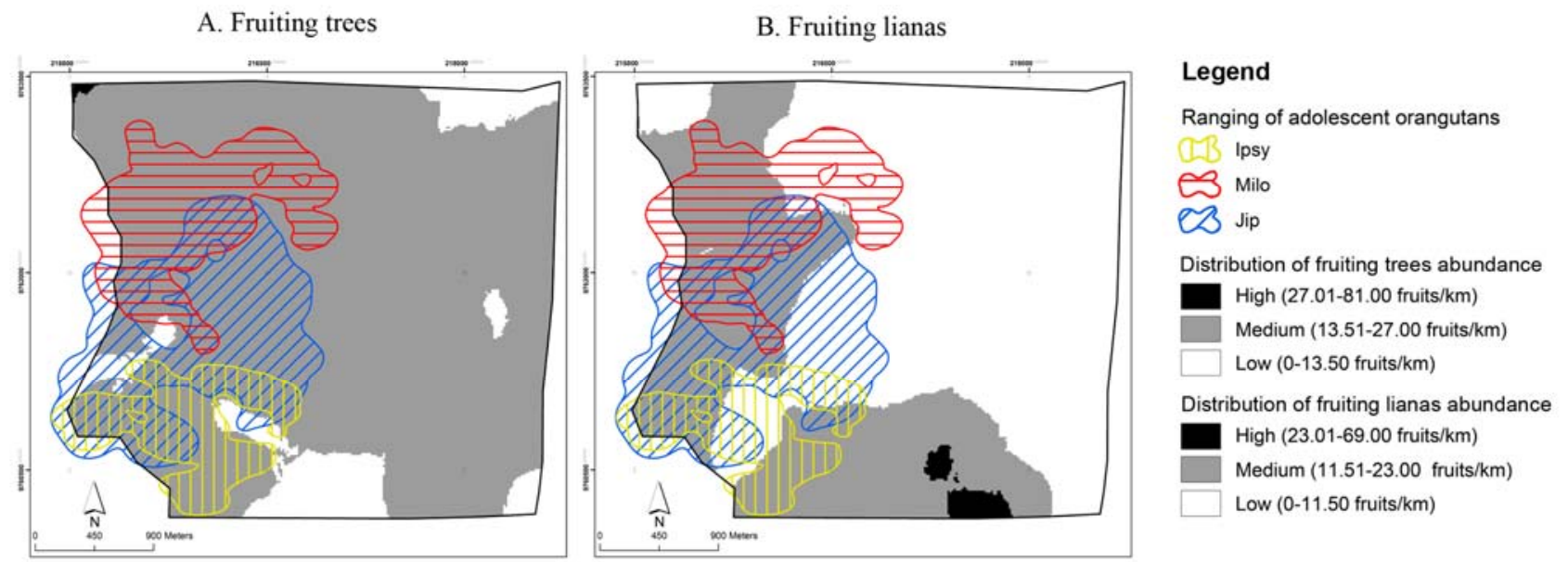

Figure 3. Overlap between home range and distribution of fruit plant abundance for one year (A. for trees and B for lianas). Note: The yellow, red, and blue depicted areas represent the calculated home ranges for the three orangutans Ipsy, Milo and Jip, respectively. 
Lianas have an important role effect on forest dynamics, including succession; depressing tree regeneration (through competition that increases tree mortality) and altering tree allometry (Schnitzer and Bongers 2002; Alvarez-Cansino et al. 2015; Barry 2015; Dias 2016). Lianas also create bridges between trees that givea ccess to mobile arboreal animals, and provide food (leaves, flowers, and fruits) for animals like primates (Schnitzer and Bongers 2002; Setia 2009). The liana abundance distribution pattern, clumped in the western and southern area, thus provides benefits for orangutans in terms of greater accessibility via liana bridges and in providing a food source.

\section{Adolescent orangutan home range and its response to fruiting plant availability}

Travel distance is defined as the total distance an individual orangutan travels per day, from the moment it leaves its nest in the morning to the moment it builds the nest for the next night (Wartmann 2010). Home range is the area that is used by an orangutan to do its daily activities, such as feeding, reproduction, and parental care within a certain period (Galdikas1988). Jip and Ipsy were still always within $50 \mathrm{~m}$ of their mothers, and as a result their traveling and ranging reflects their mothers' preferences. However, they were often feeding on other sources and made their own nests sometimes $>10 \mathrm{~m}$ away from their mothers'. The spatial analysis of travel distance in our study show that adolescent orangutans, carrying out daily activities in TORS traveled $936 \mathrm{~m}$ per day (on average; $\pm 365 ; \mathrm{n}=64$ ). Milo had the longest travel distance, followed by Jip and then Ipsy (Table 2). Meanwhile, home range for the study period showed that Jip had the largest home range, followed by Milo and finally Ipsy (Table 3). Jip's mother has a greater home range than other females (Wartmann et al. 2010; van Noordwijk et al. 2012). This results in Jip having a larger home range than Milo. Milo has a strongly overlapping home range with her mother (Mindy). Both of them range in the western part of TORS with about 178 ha (Mindy) and 169 ha (Milo). This shows phylopatry in female orangutans with a high intra-family tolerance (Wartmann et al. 2010; van Noordwijk et al. 2012). However, Ipsy's observed home range was smaller than for the other orangutans, but this may be because part of her home range is outside the TORS area and thus the number of waypoints sampled was small.

Monthly ranges varied in size every month (Table 3 ). There was no significant correlation between monthly range size and the number of waypoints ( $\mathrm{P}$-value $>0.05)$. This result showed that spatial analysis of monthly ranges using the KDE method was not affected by the number of points taken. KDE does not overestimate the home range (Seaman and Powell 1996; Laver and Kelly 2008; Wartmann et al. 2010). The results indicate that the monthly range for each month is fairly uniform and is influenced by food distribution.

The largest travel distance and monthly range for the adolescent orangutans occurred in December (Jip and Milo), and the smallest in March and August for Milo, and in May for Jip and Ipsy (Table2; Table 3andFigure 4). These conditions correlated with fruit availability in those months. According to Singleton et al. (2009), an orangutan's daily range is influenced by food sources. In our study, adolescent orangutans increased their travel distance and monthly range size in December due to high fruit availability. Orangutans did the opposite in March and May, as they decreased their travel distance and monthly range size due to low fruit availability. It is one of the orangutans' strategies to maintain energy balance (Knott et al. 1998; Morrogh-Bernard et al. 2009). Female orangutans of Jinak's family in TORS also use the same strategy to respond to the fruit availability (Wartmann et al. 2010). Generally, this strategy is used in a homogeneous habitat with a uniform gradation of fruit abundance (Singleton et al. 2009).

Table 2. Travel distance (metres) of adolescent orangutans

\begin{tabular}{|c|c|c|c|c|c|c|c|c|c|}
\hline \multirow{2}{*}{$\begin{array}{l}\text { Adolescent } \\
\text { orangutan }\end{array}$} & \multirow[b]{2}{*}{ Aug } & \multicolumn{7}{|c|}{ Travel distance } & \multirow{2}{*}{ Mean } \\
\hline & & Oct & Dec & Feb & Mar & May & Jun & Jul & \\
\hline Jip & & 1152 & 1175 & & & 617 & 664 & & 940.3 \\
\hline Milo & 942 & 1365 & 1388 & & 1082 & & 703 & & 1073.1 \\
\hline Ipsy & & & & 898 & & 624 & & 692 & 726.5 \\
\hline
\end{tabular}

Table 3. Range area (hectares) within each month, and the home range across a whole year,for the threeadolescent orangutans

\begin{tabular}{|c|c|c|c|c|c|c|c|c|c|}
\hline \multirow{2}{*}{$\begin{array}{l}\text { Adolescent } \\
\text { orangutan }\end{array}$} & \multicolumn{8}{|c|}{ Monthly ranges } & \multirow{2}{*}{$\begin{array}{c}\text { Home range } \\
\text { (one year) }\end{array}$} \\
\hline & Aug & Oct & Dec & Feb & Mar & May & Jun & Jul & \\
\hline Jip & - & 106.4 & 165.8 & - & - & 45.09 & 84.92 & - & 244.8 \\
\hline Milo & 53.8 & 101.6 & 114.2 & - & 51.43 & - & 88.84 & - & 169 \\
\hline Ipsy & - & - & - & 39.56 & - & 17.33 & - & 59.04 & 109.8 \\
\hline
\end{tabular}



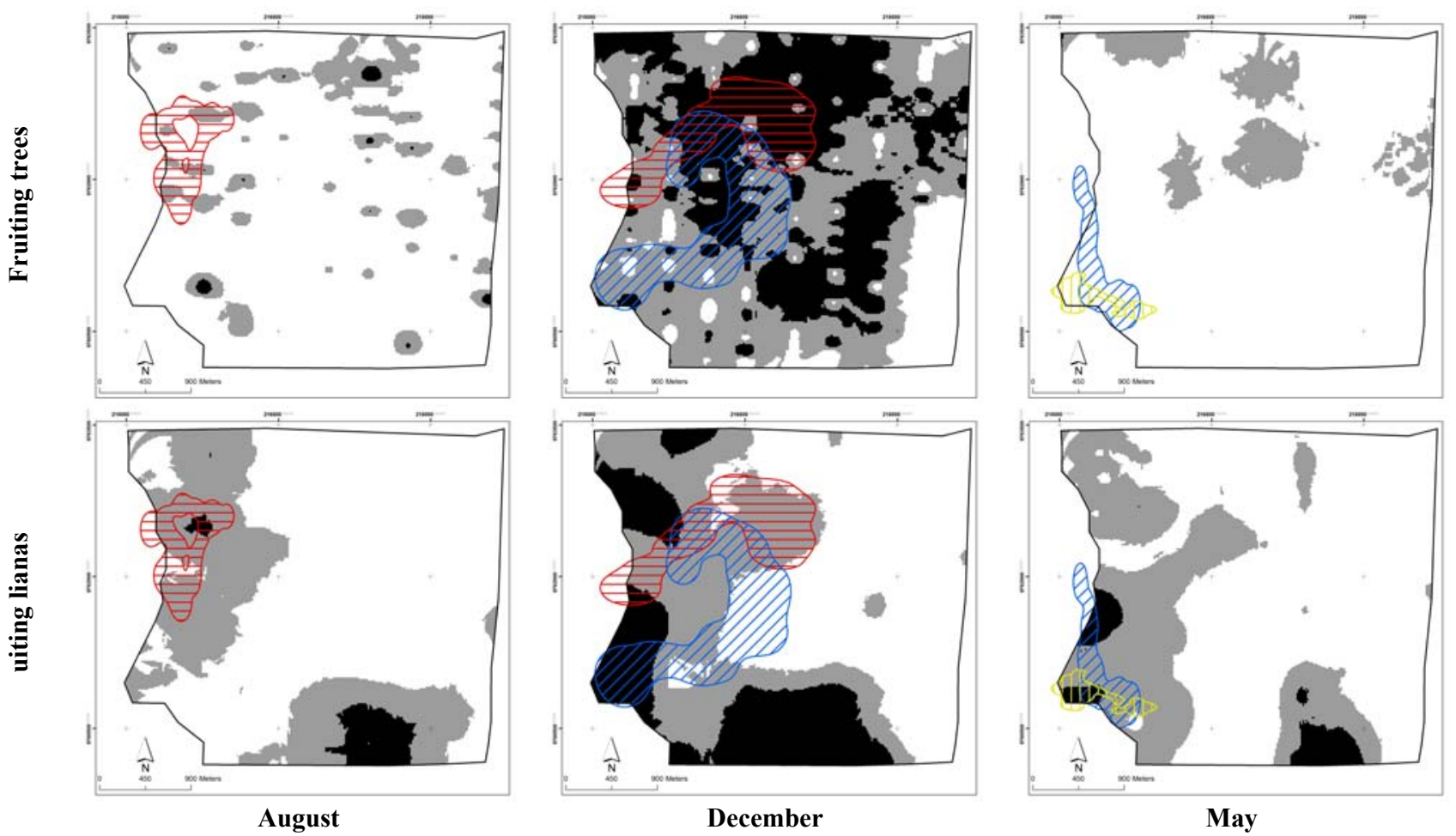

Figure 4. Orangutan monthly range overlapped with fruiting trees (top) and liana (bottom) in August (left), December (middle) and May (right). Note: See the complete legend in Figure 3; yellow, red, and blue depicted areas represent the monthly range areas for the three orangutans Ipsy, Milo and Jip, respectively

The orangutans' response to fluctuation in fruit availability was not only reflected in their home range size, but also in how they used the area in their home range (Wartmann et al. 2010). Our research showed that different utilization patterns occurred between trees and lianas by the adolescent orangutans. Jip, Milo and Ipsy were located in the western and southern areas of TORS, that consisted of medium to high abundance of liana fruit. However, the largest utilization in their home range was in area of medium abundance of fruit trees (Figure 3). The results showed that the area with medium to high abundance of tree fruit was preferred by the orangutans compared to the areas of abundant liana fruit.

Each month, adolescent orangutans used the part of their home range which was located in areas with a high to medium abundance of fruit trees. This condition occurred nearly every month, except during the period of low fruit tree availability (August and May). During the period of low tree-fruit availability, adolescent orangutans used a different area. They used areas which had a high to medium abundance of fruit lianas. Orangutans responded to a low period of fruit trees by not only decreasing their home range size, but also by changing the location of their home range to areas that had a medium to high abundance of liana fruit (Table 4). Liana fruits, leaves and flowers are an important food for frugivorous primates in TORS during the period of low availability of fruit trees (Vogel et al. 2009). Orangutan in TORS generally also consume inner bark, pith, young leaves, flowers as a fallback food (Bastian et al. 2010; Vogel et al. 2016).

Future research should focus attention on adolescent orangutans located in eastern TORS where the abundance of fruiting liana is low, and so adolescent orangutans maybe feeding on other alternative foods.

In conclusion, adjusting range use to fruit availability is an important survival strategy for orangutans. The process of responding adaptively to variability in fruit availability begins in adolescence. In our study, adolescent orangutans responded to months of low fruit availability (from trees) by decreasing their monthly range. In addition, they also changed the utilization area in their monthly range to locations that consisted of medium to high abundance of liana fruit. This ranging behavior is an adaptation that optimizes use of low quality habitat in order to survive in a degraded forest landscape. 
Table 4. The proportions (\%) of each orangutan's range within high, medium and low levels offruit productivity; from trees on the one hand and from lianas on the other; monthly data, as well as data across one year

\begin{tabular}{|c|c|c|c|c|c|c|}
\hline & \multicolumn{3}{|c|}{ Tree } & \multicolumn{3}{|c|}{ Liana } \\
\hline & High & Medium & Low & High & Medium & Low \\
\hline \multicolumn{7}{|l|}{ Jip } \\
\hline October & $0 \%$ & $80.0 \%$ & $20.0 \%$ & $0 \%$ & $27.3 \%$ & $72.7 \%$ \\
\hline December & $39.5 \%$ & $56.3 \%$ & $4.2 \%$ & $19.0 \%$ & $45.4 \%$ & $35.6 \%$ \\
\hline May & $0 \%$ & $0 \%$ & $100 \%$ & $26.8 \%$ & $71.3 \%$ & $1.9 \%$ \\
\hline June & $0 \%$ & $38.2 \%$ & $61.8 \%$ & $0 \%$ & $8.0 \%$ & $92.0 \%$ \\
\hline 1 Year & $0 \%$ & $94.6 \%$ & $5.4 \%$ & $0 \%$ & $58.8 \%$ & $41.2 \%$ \\
\hline \multicolumn{7}{|l|}{ Milo } \\
\hline August & $0 \%$ & $29.1 \%$ & $70.9 \%$ & $4.9 \%$ & $85.4 \%$ & $9.6 \%$ \\
\hline October & $0 \%$ & $94.6 \%$ & $5.4 \%$ & $0 \%$ & $61.7 \%$ & $38.3 \%$ \\
\hline December & $72 \%$ & $26.8 \%$ & $1.2 \%$ & $6.5 \%$ & $79.8 \%$ & $13.7 \%$ \\
\hline March & $0.3 \%$ & $99.1 \%$ & $0.6 \%$ & $2.8 \%$ & $27.8 \%$ & $69.4 \%$ \\
\hline June & $0 \%$ & $48.7 \%$ & $51.3 \%$ & $0.9 \%$ & $37.0 \%$ & $62.2 \%$ \\
\hline 1 Year & $0 \%$ & $99.6 \%$ & $0.4 \%$ & $0.0 \%$ & $66.5 \%$ & $33.5 \%$ \\
\hline \multicolumn{7}{|l|}{ Ipsy } \\
\hline February & $18.9 \%$ & $71.0 \%$ & $10.1 \%$ & $0 \%$ & $0 \%$ & $100.0 \%$ \\
\hline May & $0 \%$ & $0 \%$ & $100.0 \%$ & $37.6 \%$ & $60.2 \%$ & $2.3 \%$ \\
\hline July & $0 \%$ & $59.7 \%$ & $40.3 \%$ & $3.4 \%$ & $56.2 \%$ & $40.4 \%$ \\
\hline 1 Year & $0 \%$ & $96.7 \%$ & $3.3 \%$ & $0 \%$ & $58.2 \%$ & $41.8 \%$ \\
\hline
\end{tabular}

\section{ACKNOWLEDGEMENTS}

We thank AIM Zurich University; Faculty of Biology of Universitas Nasional Jakarta; Rutgers University; BOSF-Mawas Conservation Program; KPHL Kuala Kapuas; BKSDA Province of Central Kalimantan; BAPPEDA Province of Central Kalimantan; and Department of Biology, Institut Pertanian Bogor, Bogor, for the help and support that made this research possible. We also thank the research manager, all field assistants, and other researchers in Tuanan Orangutan Research Station who greatly helped in the field, as well as Christian Pranoto who helped during the writing. We thank Ambriansyah for help with identifying the fruit species.

\section{REFERENCES}

Abram NK, Meijaard E, Wells JA, Ancrenaz M, Pellier AS, Runting RK, Geveau D, Wich SA, Nardiyono, Tjiu A, Nurcahyo A, Mengersen K. 2015. Mapping perceptions of species' threats and population trends to inform conservation efforts: the Bornean orangutan case study. Divers Distrib 21: 1-13.

Addo-Fordjour P, Rahmad ZB, Shahrul AMS. 2012. Effects of human disturbance on liana community diversity and structure in a tropical rainforest, Malaysia: implication for conservation. J Plant Ecol5: 391399.

Alvarez-Cansino L, Schnitzer SA, Reid JP, Powers JS. 2015. Liana competition with tropical trees varies seasonally but not with tree species identity. Ecology, Ecol Soc Amer 96: 39-45.

Ariyanto T. 2015. Pattern of fruiting plant availability and space utilization in female orangutans (Pongo pygmaeus wurmbii, Tiedemann 1808) at Tuanan Research Station, Central Kalimantan. [Thesis]. Universitas Indonesia, Jakarta. [Indonesian].

Arora N, van Noordwijk MA, Ackermann C, Willems EP, Nater A, Greminger M, Nietlisbach $\mathrm{P}$, Dunkel LP, Utami Atmoko SS,
Pamungkas J, Perwitasari-Farajallah D, Van Schaik CP, Krützen M.2012. Parentage-based pedigree reconstruction reveals female matrilineal clusters and male-biased dispersal in non gregarious Asian great apes, the Bornean orang-utans (Pongo pygmaeus). Mol Ecol 21 (13):3352-3362.

Ancrenaz M, Gumal M, Marshall AJ, Meijaard E, Wich SA, Husson S. 2016. Pongo pygmaeus. The IUCN Red List of Threatened Species 2016. DOI: 10.2305/IUCN.UK.2016-1.RLTS.T17975A17966347.en.

Barry KE, Schnitzer SA, van Breugel M, Hall JS. 2015. Rapid liana colonization along a secondary forest chronos equence. Biotropica 47: 672-680.

Bastian ML, Zweifel N, Vogel ER, Wich SA. 2010. Diet traditions in wild orangutans. Amer J Phys Anthropol143: 175-187.

Buij R, Wich SA, Lubis AH, Sterck EHM. 2002. Seasonal movement in the Sumatran orangutan (Pongo abelii) and consequences for conservation. Biol Conserv 107: 83-87.

Cannon CH, Curran LM, Marshall AJ, Leighton M. 2007. Beyond mastfruiting events: Community asynchrony and individual dormancy dominate woody plant reproductive behavior across seven Bornean forest types. Curr Sci 93: 1558-1566.

Cai ZQ. 2007. Lianas and Trees in Tropical Forests in South China. [Dissertation]. Wageningen University, Wageningen, The Netherland.

Dias AS, dos Santos K, dos Santos FAM, Martins FR. 2016. How liana loads alter tree allometry in tropical forests. Plant Ecol218: 119-125.

Ding Y, Zang R. 2009. Effects of Logging on the Diversity of Lianas in a Lowland Tropical Rain Forest in Hainan Island, South China. Biotropica 41: 618-624.

Galdikas BMF. 1988. Orangutan diet, range, and activity at Tanjung Puting, Central Borneo. Intl J Primato19: 1-31.

Harrison ME. 2009. Orangutan Feeding Behaviour in Sebangau, Central Kalimantan. [Dissertation]. University of Cambridge, London.

Harrison ME, Husson SJ, Zweifel N, D'Arcy LJ, Morrogh-Bernard HC, Noordwijk MA, van Schaik CP. 2013. Trends in Fruiting and Flowering Phenology with relation to abiotic variable in Borneo PeatSwamp Forest Tree Species Suitable for Restoration Activities. The Kalimantan Forests and Climate Partnership, Jakarta.

Harrison ME, Zweifel N, Husson SJ, Cheyne SM, D'Arcy LJ, Harsanto FA, Morrogh-Bernard HC, Purwanto A, Rahmadt, Santiano, Vogel ER, Wich SA, van Noordwijk MA. 2016. Disparity in onset timing and frequency of flowering and fruiting events in two bornean peatswamp forests. Biotropica 48: 188-197. 
Knot CD. 1998. Changes in orangutan caloric intake, energy balance, and ketones in response to fluctuating fruit availability. Intl J Primatol19. 1061-1079.

Laver PN, Kelly MJ. 2008. A critical review of home range studies. J Wildlife Manag 72: 290-298.

Ledo A, Schnitzer SA. 2014. Disturbance and clonal reproduction determine liana distribution and maintain liana diversity in a tropical forest. Ecology Ecol Soc Amer 95: 2169-2178.

Letcher SG. 2014. Patterns of liana succession in tropical forests. In Schnitzer SA, Bongers F, Burnham RJ, Putz FE (eds) Ecology of Liana. John Wiley \& Sons, Ltd, Chichester, UK.

Mkrtchyan A. 2004. Spatial interpolation of field data on plant abundance. In: Commarmot B, Hamor FD (eds) Proceedings International Conference. Federal Research Institute WSL, Birmensdorf, 13-17 October2004.

Morrogh-Bernard HC, Husson SJ, Knott CD, Wich SA, van Schaik CP, van Noordwijk MA, Lackman-Ancrenaz I, Marshall AJ, Kanamori T, Kuze N et al. 2009. Orangutan Activity Budgets and Diet: A Comparison Between Species, Populations, and Habitats. In: Wich SA, Atmoko SSU, Setia TM, van Schaik CP (eds). Orangutans: Geographic variation in behavioral ecology and conservation. Oxford University, New York.

Morrogh-Bernard HC, Morf NV, Chivers DJ, Krutzen M. 2011. Dispersal patterns of orangutans (Pongo spp.) in a Bornean peat-swamp forest. Intl J Primatol 32: 362-376.

Page SE, Rieley JO, Shotyk ØW, Weiss D. 1999. Interdependence of peat and vegetation in a tropical peat swamp forest. Phil Trans R Soc B Biol Sci 354: 1885-1897.

Russon AE, Wich SA, Ancrenaz M, Kanamori T, Knott CD, Kuze N, Morrogh-Bernard HC, Pratje P, Ramlee H, Rodman P et al. 2009. Geographic variation in orangutan diets. In:Wich SA, Atmoko SSU, Setia TM, van Schaik CP (eds) Orangutans: Geographic Variation in Behavioral Ecology and Conservation. Oxford University, New York.

Schnitzer SA, Carson WP. 2001. Treefall gaps and maintenance of species diversity in a tropical forest. Ecology 82: 913-919.

Schnitzer SA, Bongers F. 2002. The ecology of lianas and their role in forests. Trends Ecol Evol 17: 223-230.

Seaman DE, Powell RA. 1996. An evaluation of the accuracy of Kerne density estimators for home range analysis. Ecology 77: 2075-2085.

Setia TM. 2009. The role of liana in orangutan life. Vis Vitalis 2: 55-61. [Indonesian]

Singleton I, van Schaik CP. 2001. Orangutan home range size and its determinants in a Sumatran Swamp Forest. Intl J Primatol22: 877911.

Singleton I, Knott CD, Morrogh-Bernard HC, Wich SA, van Schaik CP. 2009. Ranging behavior of orangutan females and social organization.
In: Wich SA, Atmoko SSU, Setia TM, van Schaik CP (eds) Orangutans: Geographic Variation in Behavioral Ecology and Conservation. Oxford University, New York.

Soehartono T, Susilo HD, Andayani N, Atmoko SSU, Sihite J, Saleh C, Sutrisno A. 2009. Orangutan Indonesia: Conservation Strategies and Action Plan 2007-2017. Directorate General of Forest Protection and Nature Conservation, Ministry of Forestry, Jakarta.

van Noordwijk MA, Arora N, Willems EP, Dunkel LP, Amda RN, Mardianah N, Ackermann, Krutzen M, van Schaik CP. 2012. Female philopatry and its social benefits among Bornean orangutans. Behavior Ecolsociobiol66: 823-834.

van Schaik CP, Azwar, Priatna D. 1995. Population estimates and habitat preferences of orangutans based on line transects of nests. In: Nadler RD, Galdikas BMF, Sheeran LK, Rosen N (eds) The Neglected Ape. Springer, New York.

van Schaik CP, Wich SA, Atmoko SSU and Odom K. 2005. A Simple Alternative to line transect of nests for estimating orangutan densities. Primates 46: 249-254.

van Schaik CP, van Noordwijk MA. 2013. Standardized field methods. http://www.aim.uzh.ch/de/research/orangutannetwork/sfm.html.

Vogel ER, Haag L, Setia TM, van Schaik, Dominy JN. 2009. Foraging and ranging behavior during a fallback episode: Hylobates albibarbis and Pongo pygmaeus wurmbii compared. Amer J Phys Anthropol140:716-726.

Vogel ER, Harrison ME, Zulfa A, Bransford TD, Alavi SE, Husson SJ, Morrogh-Bernard HC, Santiano, Firtsman T, Atmoko SCU et al. 2015. Nutritional differences between two orangutan habitats: Implications for population density. PLoS One 10(10): e0138612. DOI: 10.1371/journal.pone.0138612.

Vogel ER, Alavi SE, Utami-Atmoko SC, van Noordwijk MA, Bransford TD, Erd WM, Zulfa A, Sulistyo F, Farida WR, Rothman JM. Nutritional ecology of wild Bornean orangutans (Pongo pygmaeus wurmbii) in a peat swamp habitat: Effects of age, sex, and season. Amer J Primatol79: 1-20.

Wartmann FM, Purves RS, van Schaik CP. 2010. Modelling ranging behavior of female orangutans: a case study in Tuanan, Central Kalimantan, Indonesia. Primates 51: 119-130.

Wich SA, Meijaard E, Marshall AJ, Husson S, Ancrenaz M, Lacy RC, van Schaik CP, Sugardjito J, Simorangkir T, Traylor-Holzer K et al. 2008. Distribution and conservation status of the orangutan (Pongo spp.) on Borneo and Sumatra: how many remain? Oryx 42: 329-339.

Wich SA, Vogel ER, Larsen MD, Frediksson G, Leighton R, Yeager CP, Brearley FQ, van Schaik CP and Marshall AJ. 2011. Forest fruit production is higher on Sumatra than on Borneo. PLoS One 6: e21278. DOI: 10.1371/journal.pone.0021278. 